\title{
Ballistic Characteristics of Rocket Projectile with Deflection Nose
}

\author{
Xu yongjie ${ }^{1}$, Wang zhijun ${ }^{1}$, Wu guodong ${ }^{1}$, Yi jianya ${ }^{1}$, Pan shouli ${ }^{2}$
}

1. College of Mechatronic Engineering,North University of China,Taiyuan 030051.

2. No.208 Research Institute of China Ordnance Industries,Beijing 102202

Keywords: intelligent morphing; self-adaptive control; nose deflection; dynamics characteristics

\begin{abstract}
Deflection nose is a new concept of fast response control mode, partial nose of projectile can deflect certain angle relative to the axis of projectile body and pressure difference emerges in the windward and leeward side of warhead then generates aerodynamic control force, and this control way has high control efficiency and very good application prospect in the ammunition system. Nose deflection actuator based on smart material and structure makes projectile body morphing then obtains additional aerodynamic force and moment, changes the aerodynamic characteristics in the projectile flight process, produces the corresponding balance angle, sideslip angle then resulting in motor overload, adjusts flight moving posture and controls the ballistics, finally realizes shooting range changing and improves firing accuracy. In order to study characteristics of self-adaptive control projectile, numerical simulations were conducted by fluid dynamics software ANSYS FLUENT for fin stabilized rocket projectile. Computed aerodynamics on different nose delectation angle, different Mach number and different angle of attack, and compared the aerodynamic characteristics with the different nose deflection angles. Results show that the nose deflection control has bigger influence on the head of rocket projectile, and caused asymmetry of the flow field structure, make the warhead differential pressure in the windward and leeward surface increases, resulting in a larger lift. Finally, ballistics experiments were done for verification. Results can offer theoretical basis for self-adaptive rocket projectile design and optimization also provides new ideas and methods for field smart ammunition research.
\end{abstract}

\section{Introduction}

Smart, intelligent and high mobility of ammunition is the important development direction of ammunition technology in a long historical period in the future[1-3], research and develop active detective and identify target, self-adaptive ballistic correction and autonomous attack smart ammunition by applying various innovative intelligent control technology, simple guidance or ballistic adaptive ways has become research focus of the world's national defense science and technology.

Intelligent morphing technology means that shape of aircraft self-adaptive changes according to flight mission, flight speed, and flight environment, it using intelligent material or structure realizes actively, adaptively and continuous changes in appearance, meets different mission with different aerodynamic layout, so as to achieve performance optimization of aerodynamic and flight[4-7]. For modern high mobility weapons, it can solve the contradictions of different aerodynamic layouts aircraft designed by intelligent morphing technology and also improve the economic efficiency and operational capability.

Human beings are dedicated to developing the lighter and more intelligent missile now and even for quite far future. Research on the creative intelligent control technology has very important significance and practical value, where the external ballistics plays a key role in this modern missile control technology.

\section{Modeling}

\subsection{Geometrical Model}

3D model of simplified standard fin stabilized rocket projectile as shown in Figure1, where length $\mathrm{L}=600.0 \mathrm{~mm}$, diameter $\mathrm{D}=90.0 \mathrm{~mm}$, and rocket projectile with nose deflection angle as shown 
in Figure 2.

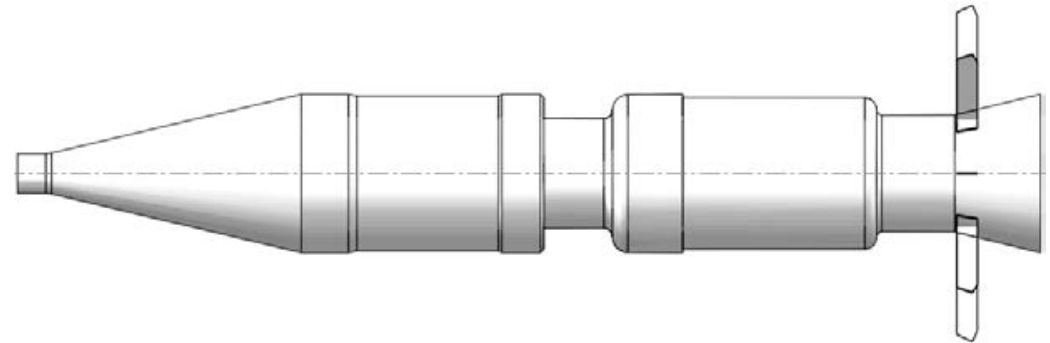

Figure 1: Standard fin stabilized rocket projectile

\subsection{Mass Properties}

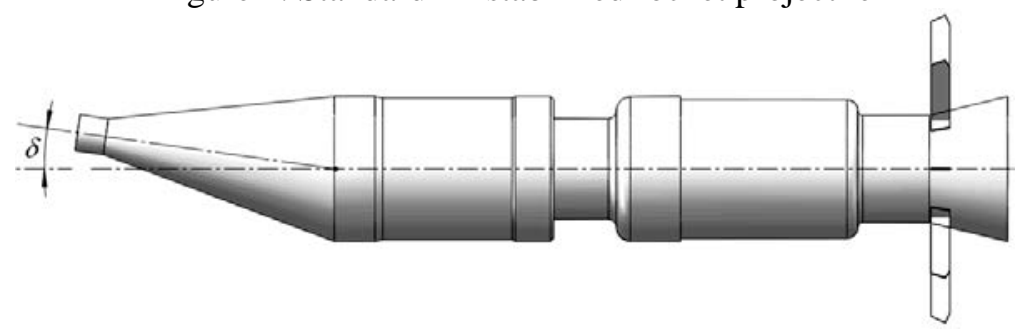

Figure 2: Rocket projectile with nose deflection angle

Build trajectory correction rocket projectile model with different nose deflection angle, and the nose delfection angle respectively is $0^{\circ} 、 2^{\circ} 、 4^{\circ} 、 6^{\circ} 、 8^{\circ} 、 10^{\circ}$, mass properties of each model as shown in Table 1.

Table 1: Mass properties

\begin{tabular}{ccccc}
\hline \multirow{2}{*}{$\begin{array}{c}\text { Number } \\
\text { code }\end{array}$} & \multirow{2}{*}{$\begin{array}{c}\text { Nose deflection } \\
\text { angle } \delta /{ }^{\circ}\end{array}$} & \multicolumn{2}{c}{ Centroid coordinate $(\mathrm{X}, \mathrm{Y}, \mathrm{Z})$} \\
\cline { 3 - 5 } & & $\mathrm{X} / \mathrm{mm}$ & $\mathrm{Y} / \mathrm{mm}$ & $\mathrm{Z} / \mathrm{mm}$ \\
\hline M0 & 0 & 331.406 & 0.000 & 0.000 \\
M1 & 2 & 331.889 & 0.263 & 0.000 \\
M2 & 4 & 332.034 & 0.523 & 0.001 \\
M3 & 6 & 332.274 & 0.778 & 0.001 \\
M4 & 8 & 332.608 & 1.024 & 0.001 \\
M5 & 10 & 333.035 & 1.259 & 0.002 \\
\hline
\end{tabular}

\subsection{Aerodynamic Force}

According to ballistic theory[8-9], in the flight of the projectile, regardless of the spinning, in order to measure the effects from each force and join force, forces and moments are simplified to the centroid of projectile. Convenient for illustrating it is given in Figure 3.

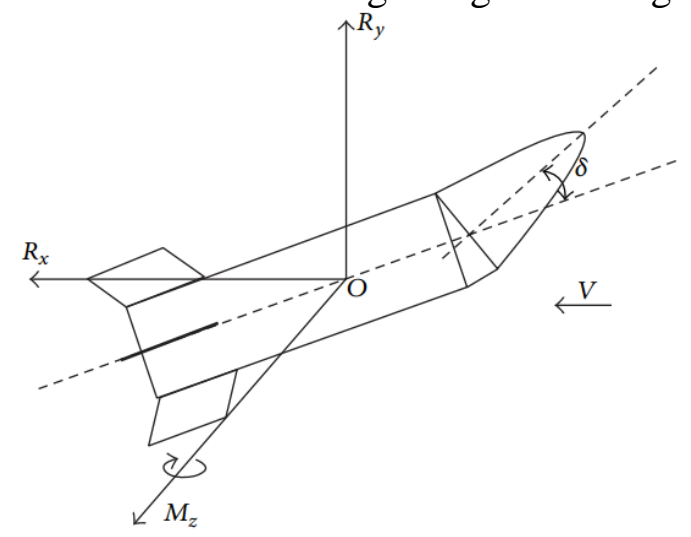

Figure 3: Diagram for simplifying aerodynamic forces

(1) $R_{x}$ is drag and expressed as $R_{x}=\left(\frac{\rho V^{2}}{2}\right) S_{M} C_{x}$

Where, $C_{x}$ is drag coefficient and $S_{M}$ is reference area $\left(\mathrm{m}^{2}\right)$. 
(2) $R_{y}$ is lift and expressed as $R_{y}=\left(\frac{\rho V^{2}}{2}\right) S_{M} C_{y}$

Where, $C_{y}$ is drag coefficient and $S_{M}$ is reference area $\left(\mathrm{m}^{2}\right)$.

(3) $M_{z}$ is static moment and expressed as $M_{Z}=\left(\frac{\rho V^{2}}{2}\right) S_{M} m_{z}$

Where, $m_{z}$ is moment coefficient.

\section{Ballistic Flight Flow Field Simulation}

Mach number range in simulation respectively is $0.8 、 1.0 、 1.2 、 2.0 、 3.0$, involving the subsonic, transonic and supersonic speed range, and nose deflection angle is $0^{\circ} 、 2^{\circ} 、 4^{\circ} 、 6^{\circ} 、 8^{\circ} 、 10^{\circ}$, and obtained the dynamics parameters such as flow field velocity and pressure, drag coefficient, lift coefficient, and pitching moment coefficient by simulation. In computational procedure using single equation model Spalart-Allmaras in turbulence model[10-13], which is only solving a transport equation about the eddy viscosity and reach good results involving wall limit flow problem and inverse pressure gradient of boundary layer problem, it commonly used in aerodynamic problems such as aircraft, flow around airfoil flow field analysis

\subsection{Pressure Field Analysis}

Typical simulation results of pressure field distribution as shown in Figure 4. Figure 4-a is the pressure nephogram and Figure 4-b is the pressure contour line.

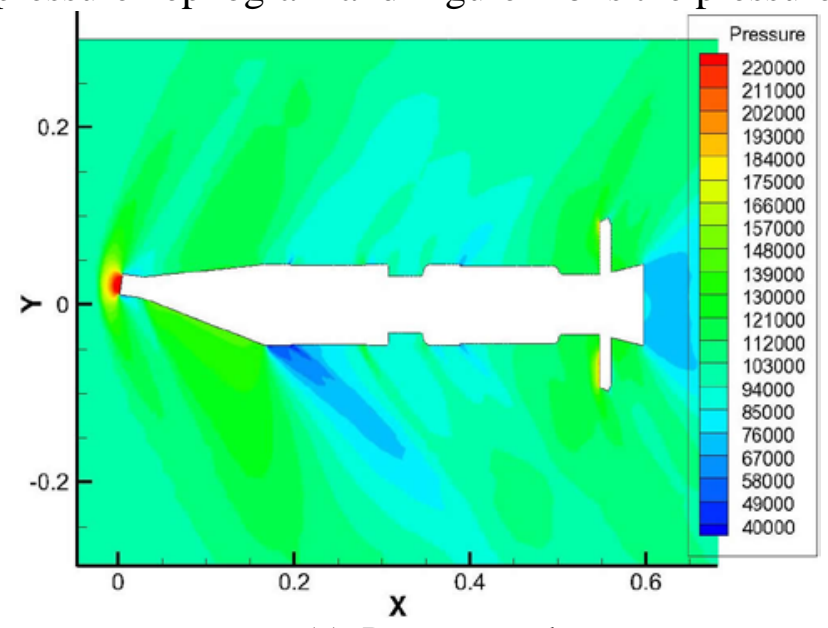

(a). Pressure nephogram

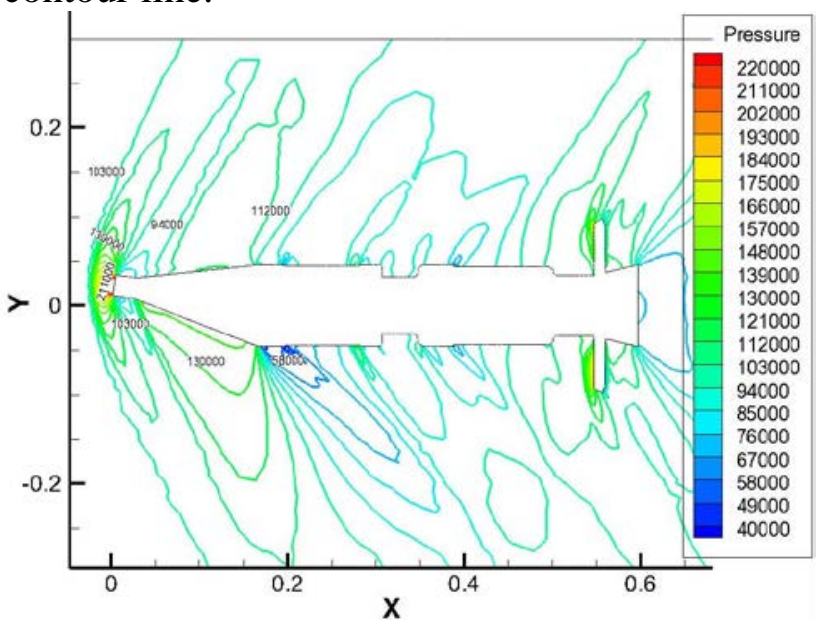

(b). Pressure contour line

Figure 4: Pressure field distribution

As shown in Figure 4, the pressure on projectile increase with deflection angle. Nose deflection angle $10^{\circ}$ has a mutation pressure because of its surface not continuous. The greater deflection angle the more obvious mutation pressure.

The warhead is the most stressful part of the whole projectile, whereby ballistic cap is the most stressful part in the warhead, pressure is growing with the increase of Mach number, pressure region has a tendency to gradually expand and gradually move to rear-ended of rocket.

When air flow through pressure region, there is an inflection point of pressure at the shoulder of rocket, then gas expansion wave emerged. At the same time, a low pressure area emerges in the area near bottom of the projectile, and it smaller and smaller when the Mach number increasing, and speed difference is more and more obvious. This is due to rocket empennage impede air flow, gas choking phenomenon appeared in the empennage leading edge, dilatational wave appear in the empennage trailing edge, and the interaction leading edge and trailing edge flow field at the same time formed the tail flow field.

In addition, it can be seen that the pressure flow field distribution is asymmetric, and the asymmetry intensified following increase of deflection angle. Because of the existence of nose deflection angle, in front of the shoulder, with the increase of deflection angle, pressure coefficient 
in windward side larger than the leeward side, in the back of shoulder, with the increase of deflection angle, pressure coefficient diminish in windward side and increase in leeward side, windward side pressure coefficient is less than the leeward side pressure coefficient.

\subsection{Velocity Field Analysis}

Typical simulation results of pressure field distribution as shown in Figure 5. Figure 5-a is the pressure nephogram and Figure 5-b is the pressure contour line.

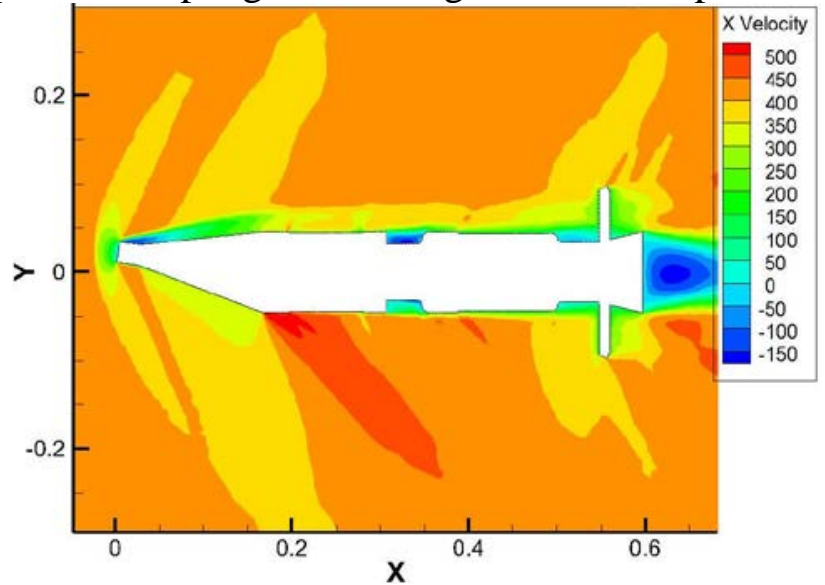

(a). Velocity nephogram

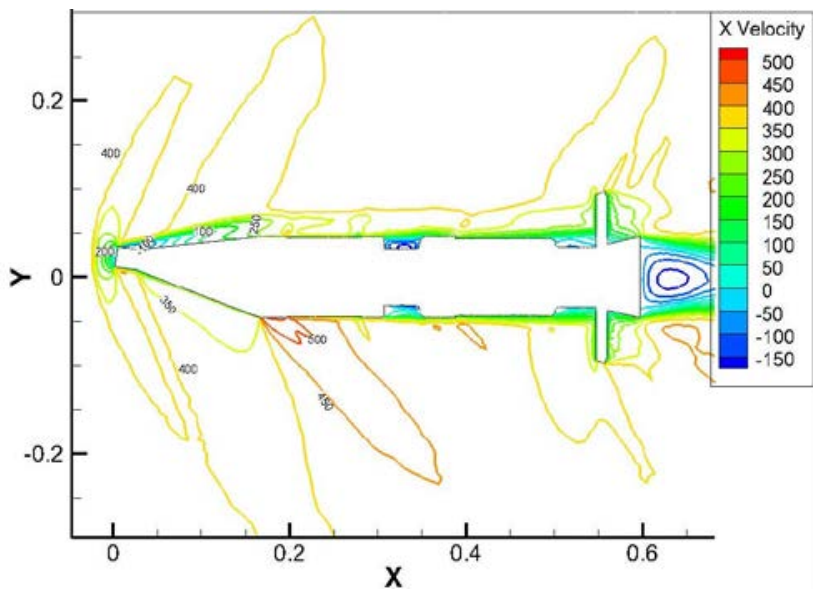

(b). Velocity contour line

Figure 5: Velocity field distribution

As shown in Figure 5, a high pressure area emerges around warhead in the flight process of external ballistics, vortex area and stress concentration around tail.

Deflection angle has important influence for tail flow field. The larger deflection angle the greater impact. Circle flow field changes a lot because of the warhead deflection angle. With the increase of deflection angle the rocket overall speed slowdown, the head velocity is small, the low speed region is larger caused by warhead and move to rear-ended of rocket.

The larger deflection angle the greater impact on the warhead flow field structure and the less impact on the downstream flow field and tail flow field asymmetry increase with the increment of deflection angle, and the greater deflection angle the greater warhead disturbance impact on the tail flow field. High speed area emerges in the warhead and expansion wave in the shoulder at the same time.

There also is a speed-jump in the shoulder windward side because of existence of attack angle, and the larger Mach number the larger speed-jump area. The fluid velocity is low in the empennage leading-edge area and choking phenomenon because of its retardation, a series of smaller spiral also emerge in the tail flow field due to speed difference caused by projectile disturbance.

\subsection{Aerodynamic Characteristics}

Calculation of drag coefficient as shown in Figure 6, change laws of each model is consistent and curves change smoothly.

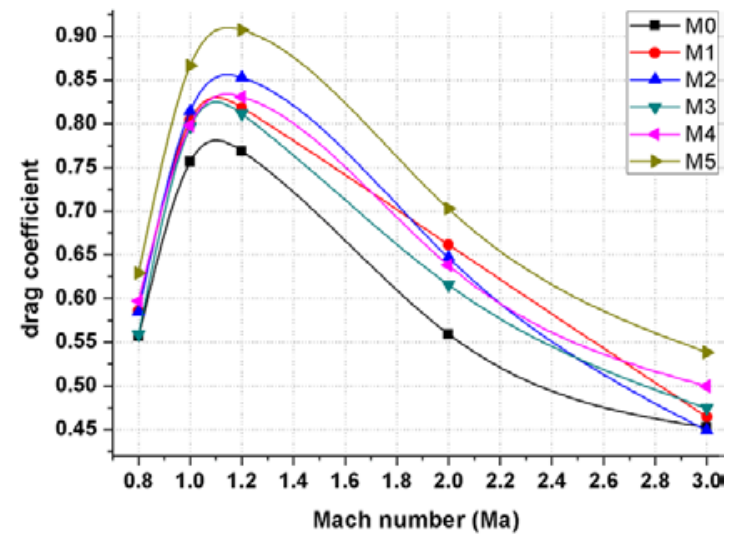

Figure 6: drag coefficient when attacking angle is $0^{\circ}$

Under the condition of same Mach number when the attacking angle is $0^{\circ}$, aerodynamic drag coefficient change smaller along with change of nose deflection angle. By comparing large amounts of simulation data, rocket projectile's aerodynamic performance is poor in the subsonic and 
transonic velocity range and aerodynamic lift and control torque is very limited in the subsonic velocity range.

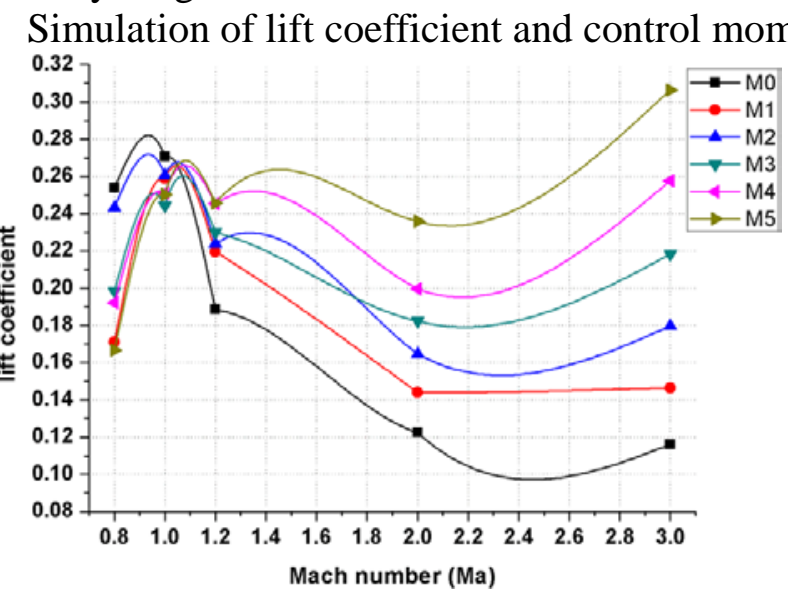

(a): lift coefficient

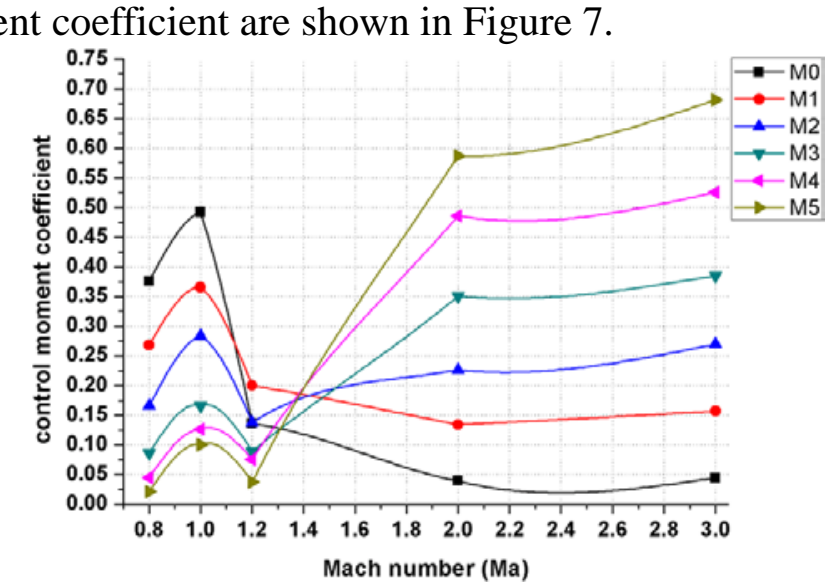

(b): control moment coefficient

Figure 7: aerodynamic coefficient when attacking angle is $2^{\circ}$

Lift coefficient and additional control torque changes obviously when the attacking angle is $2^{\circ}$ and aerodynamic performance changes significantly. Aerodynamic lift and control moment caused by nose deflection angle is objective and the smaller nose deflection angle can produce large aerodynamic controlling force.

Control mode of nose deflection can provide greater aerodynamic lift and torque control than rocket projectile with no nose deflection angle. Lift coefficient ratio and control moment coefficient ratio of rocket projectile with different nose deflection angle as shown in Table 2.

In the supersonic velocity range, nose deflection angle is $10^{\circ}$, can provide the aerodynamic lift is 2.64 times than that with no nose deflection angle and control moment is 15.28 times.

Table 2: Calculated results of coefficient ratio

\begin{tabular}{cccc}
\hline $\begin{array}{c}\text { Model } \\
\text { code }\end{array}$ & $\begin{array}{c}\text { Nose deflection } \\
\text { angle } \delta / ~^{\circ}\end{array}$ & $\begin{array}{c}\text { Lift coefficient } \\
\text { ratio }\end{array}$ & $\begin{array}{c}\text { control moment coefficient } \\
\text { ratio }\end{array}$ \\
\hline M1 & 2 & 1.26 & 3.52 \\
M2 & 4 & 1.55 & 6.05 \\
M3 & 6 & 1.88 & 8.63 \\
M4 & 8 & 2.22 & 11.78 \\
M5 & 10 & 2.64 & 15.28 \\
\hline
\end{tabular}

\section{Experimental Study}

Improving design based on rocket projectile and do experiments for ballistic correction rocket projectile with nose deflection angle $5^{\circ}$, there are 5 ballistic correction rocket projectiles prepared for the flying experiment[14-15]. Testing arrangement as shown in Figure 8

Intercept $200.00 \mathrm{~m}$ distance in the shooting range direction and determine the distance between the aiming point and fall point as transverse correction range, marked as $\Delta X$.

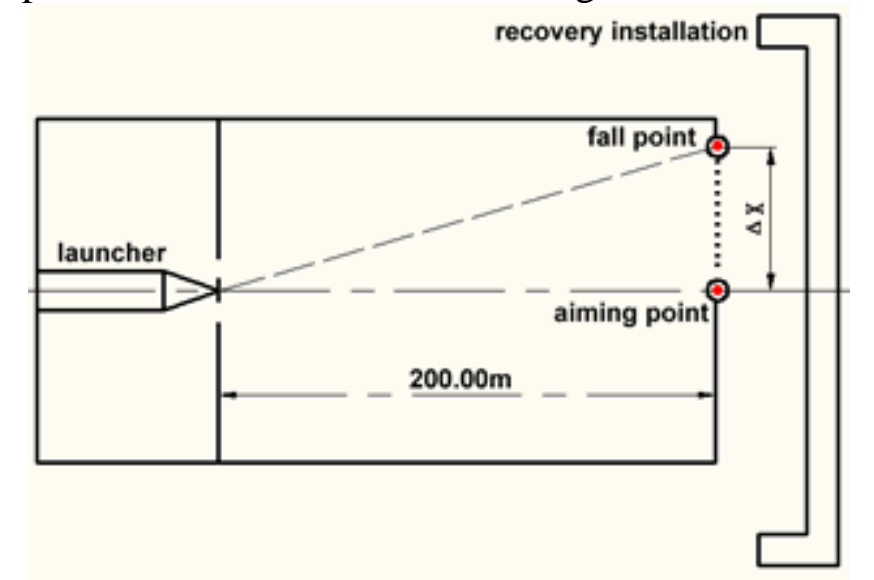


Figure 8: Diagram of testing arrangement

Experimental ballistic correction rocket projectiles with nose deflection angle $5^{\circ}$ are shown in Figure 9.
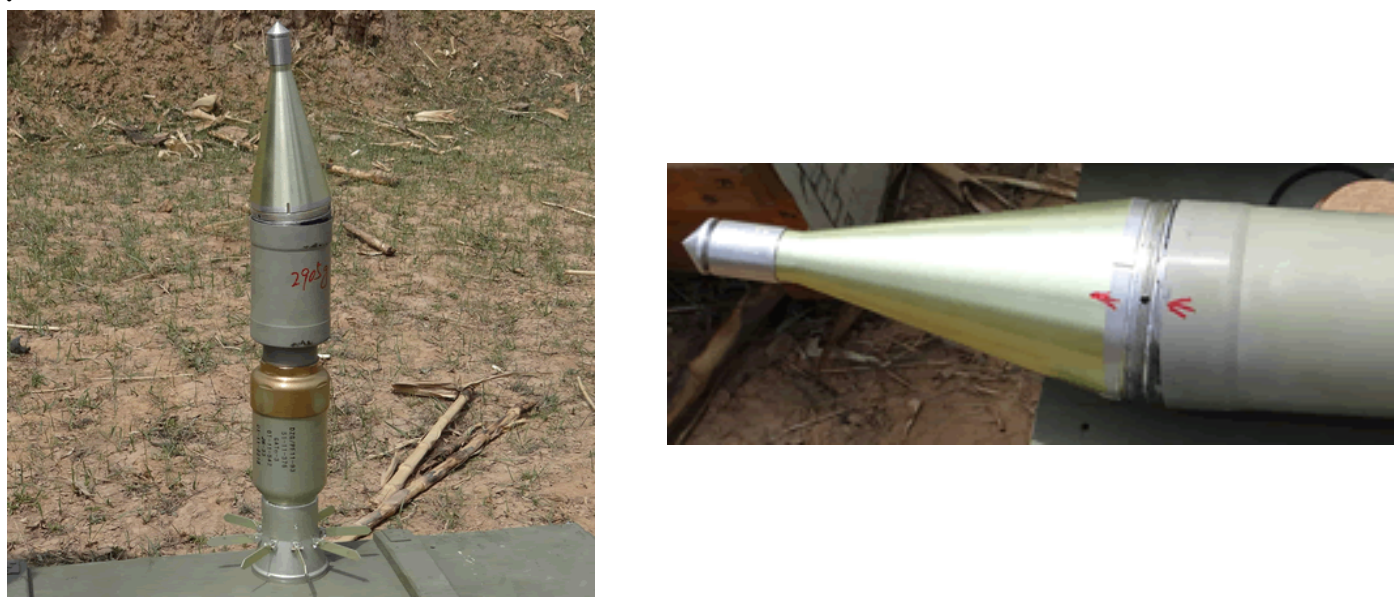

Figure 9: Experimental ballistic correction rocket projectile and its local features

In order to convenient verification, set the nose deflection angle toward to the same launch direction and measure the distance of aiming point and fall point as the horizontal correction range caused by nose deflection angle, the experimental results are shown in Table 3. Results show that under the condition of velocity is $151.06 \mathrm{~m} / \mathrm{s}$ and nose deflection angle is $5^{\circ}$, the ballistic correction rocket projectile can obtain $0.43 \mathrm{~m}$ horizontal correction range on average.

Table 3: horizontal correction value

\begin{tabular}{cccc}
\hline Number & $\begin{array}{c}\text { Firing ranges } \\
/ \mathrm{m}\end{array}$ & $\begin{array}{c}\text { Correction value } \\
\Delta X / \mathrm{m}\end{array}$ & $\begin{array}{c}\text { Flight velocity } \\
/ \mathrm{ms}^{-1}\end{array}$ \\
\hline$\# 1$ & & 0.44 & 148.40 \\
$\# 2$ & & 0.42 & 149.80 \\
$\# 3$ & 200.00 & 0.48 & 152.60 \\
$\# 4$ & & 0.39 & 152.20 \\
$\# 5$ & & 0.42 & 152.30 \\
average & 200.00 & 0.43 & 151.06 \\
\hline
\end{tabular}

\section{Conclusions}

From the simulation calculation and ballistic experiment on deflectable nose rocket projectile, the following conclusions can be obtained.

1) Large number of aerodynamic simulation show that the nose deflection angle can achieve desired aerodynamic lift, aerodynamic drag and additional torque control, it can correct ballistic trajectory effectively and realizes rocket projectile maneuvering flight.

2) Ballistic correction rocket projectile has fine pneumatic control characteristics in the supersonic velocity range and limited aerodynamic performance in the subsonic velocity range. Nose deflection has greater influence on warhead flow field structure, and smaller impact on the downstream.

3) Along with the increase of nose deflection angle, pressure on the rocket body increase especially the pressure mutation on the area ground the shoulder the rocket flow field change dramatically and pressure bigger along with the deflection angle larger, expansion waves emerge in the shoulder and low pressure area at the bottom of the projectile, and asymmetry of the flow field is bigger, differential pressure on the windward and leeward surface increases, then resulting in larger lift.

4) Flight test shows that flying control method of nose deflection is feasible and reliable and it can be used for engineering research in the further research. 


\section{References}

[1] Yin Jian-Ping, Wang Zhi-Jun. Ammunition Theory[M]. Beijing Institute of Technology Press,2014.

[2] Zhang Bo, Wang Shu-Shan, Cao Meng-Yu, Xu Yu-Xin. Impacts of deflection nose on ballistic trajectory control law. Mathematical Problems in Engineering. Volume 2014, Article ID 984840,6 pages.

[3] Gao Ting-Xin. Study of Aerodynamic Characteristics of Migraine Control[C].Aviation Aircraft Development and Aerodynamics Seminar, Lake in Hangzhou, 2006.

[4] Zhang Tong, Zhao Xiao-Li. Analysis of Trajectory Correction Projectile and its Key Technology[J].Cruise Missile, 2014,vol.24,no.5,pp.38-42.

[5] Landers M G, Hall, L H, Auman, L M and Vaughn, M E. Deflectable Nose and Canard Controls For a Fin-Stabilized Projectile At Supersonic and Hypersonic Speeds[R].AIAA-2003.

[6] Xia Bin, Zhou Liang. Trajectory Correction Projectile and Analysis on the key Technologies for the Trajectory Correction Process[J]. National Defense Science \& Technology, 2013, vol.34, no.3, pp.27-33.

[7] Vaughn, M E and Auman, L M. Assessment of a productivity-Oriented CFD Methodology for Designing a Hypervelocity Missile[C].AIAA 03-3937, in $21^{\text {st }}$ AIAA Applied Aerodynamics Conference, Orlando(FL),2003,pp.23-29.

[8] Han Zi-Peng. Exterior Ballistics of Projectile and Rockets[M]. Beijing Institute of Technology Press,2014.

[9] Xu Ming-You. Advanced External Ballistics[M].Higher Education Press, 2003.

[10] Yu Wen-Jie. Study of Aerodynamic Characteristics for a Fin-stabilized Projectile with a Deflectable Nose Control[D]. Nanjing,Nanjing University of Science\&Technology,2010.

[11] Wang Fei, Wu Guo-Dong, Wang Zhi-Jun. Numerical Calculation of Aerodynamic Characteristics of Shell with Attack Angle at the Shell Head[J], Journal of North China Institute of Technology, 2005, vol.26,no.3,pp.177-179.

[12] Wei Fang-Hai,Wang Zhi-Jun,Yin Jian-Ping. Numerical Calculation of Aerodynamic Characteristics of Shell with an Angle of Warhead [J].Journal of Projectiles, Rockets, Missiles and Guidance., 2006, vol.26, no.1, pp.553-558.

[13] Dong Er-Bao. Research on Realization Mechanism and some key Technologies of Smart Morphing Aircraft Structures [D].University of Science and Technology of China,2010.

[14] Xu Yu-Xin, Wang Shu-Shan. Armor-piercing Experiment on Fragment against Sandwich Plate with Fiber Reinforced Composite Cores[J]. Acta Materiae Compositae Sinica, 2012,vol.29,no.3,pp.72-78,.

[15] Xu Yu-Xin, Wang Shu-Shan. Armor-piercing ultimate of Tungsten Alloy Spherical Fragment against Low-carbon Steel[J], Journal of Vibration and Shock, 2011,vol.30,no.5,pp.192-195. 